Institute of $\mathbf{F}_{\text {ood }}$ and $\mathbf{A}$ gricultural $\mathbf{S}$ ciences

\title{
Symptoms and Treatment of Low Blood Sugar ${ }^{1}$
}

\author{
Linda B. Bobroff ${ }^{2}$
}

Low blood sugar, also called hypoglycemia, can be life threatening for people with diabetes. It can be caused by eating too little food, taking too much insulin or oral diabetes medication, or being extra active. Left untreated, low blood sugar can progress to diabetic coma. Everyone with diabetes needs to know the symptoms of low blood sugar so they can take action right away.* If you work or live with someone with diabetes, you should know the symptoms and treatment too!

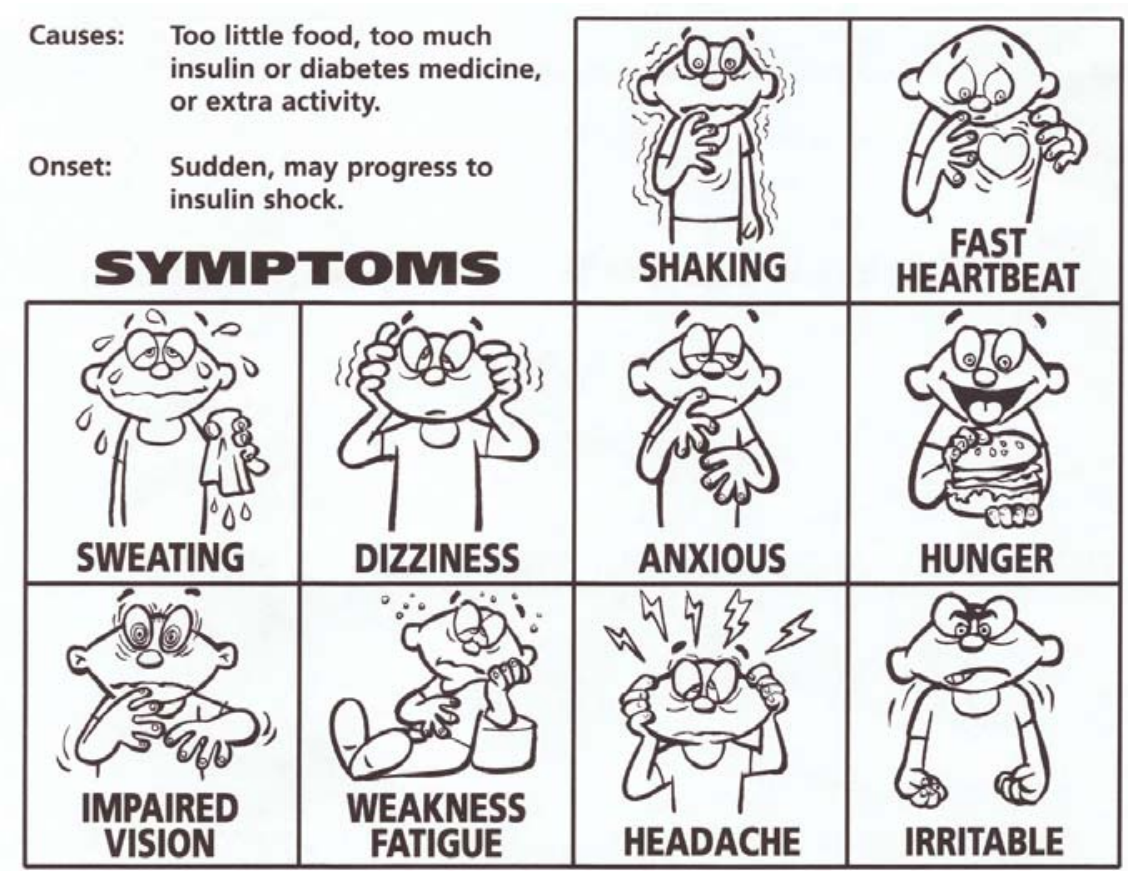

Graphic printed with permission of Novo Nordisk Pharmaceuticals, Inc.

*The only way to know for sure that your blood sugar is low is to test it with your meter.

1. This document is FCS8749, one of a series of the Department of Family, Youth and Community Sciences, Florida Cooperative Extension Service, Institute of Food and Agricultural Sciences, University of Florida. Publication : July 2002. Please visit the EDIS Web site at http://edis.ifas.ufl.edu

2. Linda B. Bobroff, PhD, RD, LD/N, associate professor, Department of Family, Youth and Community Sciences, Cooperative Extension Service, Institute of Food and Agricultural Sciences, University of Florida, Gainesville, 32611. Reviewed by Jennifer Hillan, MSH, RD, LD/N, Glenda L. Warren, MS, RD, CFCS, University of Florida, Sharon C. Valley, MS, CDE, University of Florida/Shands Diabetes Center, Tina L. Allen, MS, Columbia County Extension Service, and Nancy J. Gal, MS, Marion County Extension Service. 


\section{TREATING LOW BLOOD SUGAR}

\section{Before you feel symptoms, be prepared!}

Ask your doctor what is low blood sugar for you. That way you will know ahead of time when to treat yourself. Also ask how much sugar to take if your blood sugar is low.

Always carry pre-measured sugar. The easiest is glucose tablets or gel, sugar, or hard candy. One dose is 10 to 15 grams.

\section{When you feel symptoms:}

STEP 1. Check your blood sugar. If you can't check your blood, but feel like your sugar is low, treat it as low.

STEP 2. If your blood sugar is low (or you feel that it is low), eat sugar that will get into your blood fast.

If your blood glucose is less than $70 \mathrm{mg} / \mathrm{dL}$ :

- Eat 15 grams sugar (see list of foods).

- Wait 15 minutes and test again.

- If still below $70 \mathrm{mg} / \mathrm{dL}$, eat 15 grams again.

- Wait 15 minutes and test again. If still low, call your doctor!

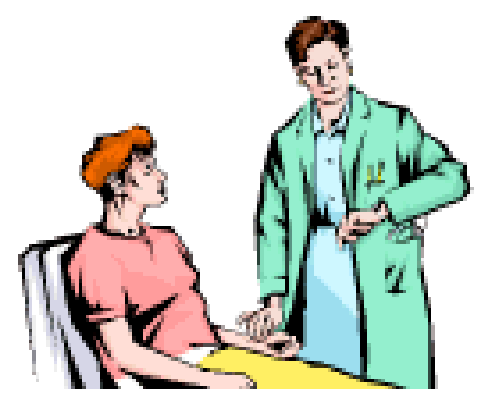

If your blood glucose is less than $50 \mathrm{mg} / \mathbf{d L}^{*}$

- Eat 30 grams sugar (see list and eat twice that amount).

- Wait 15 minutes and test again.

- If still below $70 \mathrm{mg} / \mathrm{dL}$, eat 30 grams again.

- Wait 15 minutes and test again. If still low, call your doctor!

\section{Foods with 10 to 15 grams of sugar:}

2 to 4 glucose tablets 2 teaspoons honey

2 tablespoons raisins 2 teaspoons corn

$1 / 2$ cup regular soda

$1 / 2$ cup fruit juice

5 to 7 Lifesavers ${ }^{\circledR}$

2 to 3 teaspoons sugar syrup

6 jellybeans

10 gumdrops $3 / 4$ cup to 1 cup fat free or $1 \%$ milk

Call your doctor before you take your next insulin dose or your diabetes medication.

If you will not be eating a meal within 30 minutes, have a snack with protein and carbohydrate. Snack ideas:

- Peanut butter or cheese crackers

- Half of a sandwich (cheese or meat or peanut butter)

${ }^{*} \mathrm{mg} / \mathrm{dL}=$ milligrams per deciliter of blood 